\title{
Abordagens da Controladoria nos Trabalhos do Congresso USP de Controladoria e Contabilidade: Um Enfoque nas Perspectivas Conceitual, Procedimental e Organizacional
}

\section{Approaches of Comptrollership on Papers of the USP Congress on Comptrollership and} Accounting: A Focus on Conceptual, Procedural and Organizational Perspectives

\section{Ilse Maria Beuren}

Doutora em Controladoria e Contabilidade pela FEA/USP

Professora do Programa de Pós-Graduação em Ciências Contábeis

da Universidade Regional de Blumenau - PPGCC/FURB

Endereço: Rua Antônio da Veiga, 140 - Sala D 202 - Bairro Victor Konder

CEP 89012-900 - Blumenau/SC - Brasil

E-mail: ilse@furb.br

Telefone: (47) 3321-0565

\section{Juliana Pinto}

Mestre em Ciências Contábeis pela Universidade Regional de Blumenau Endereço: Rua Antônio da Veiga, 140 - Sala D 202 - Bairro Victor Konder CEP 89012-900 - Blumenau/SC - Brasil

E-mail: julianapinto@smo.com.br

Telefone: (47) 3321-0565

\section{Vinícius Costa da Silva Zonatto}

Doutorando em Ciências Contábeis e Administração na

Universidade Regional de Blumenau

Endereço: Rua Antônio da Veiga, 140 - Sala D 202 - Bairro Victor Konder

CEP 89012-900 - Blumenau/SC - Brasil

E-mail: viniciuszonatto@gmail.com

Telefone: (47) 3321-0565

Artigo recebido em 25/05/2008. Revisado por pares em 13/01/2009. Reformulado em 03/03/2011. Recomendado para publicação em 10/01/2012 por Sandra Rolim Ensslin (Editora Científica). Publicado em 28/06/2012. 


\title{
Resumo
}

O estudo identifica a abordagem da controladoria em trabalhos publicados nos anais do Congresso USP de Controladoria e Contabilidade entre 2001 a 2006, pautado em pesquisa documental e denotação descritiva. Os resultados mostram na perspectiva conceitual que não há preocupação em definir o termo controladoria e nem sua relação com outras áreas do conhecimento. Na perspectiva procedimental, não há consenso sobre as atividades típicas, mas destaca-se a relativa aos sistemas de informação. Na perspectiva organizacional, não é focalizada a controladoria como unidade organizacional formalmente constituída, com poder de decisão, mas sim como unidade administrativa que subsidia a tomada de decisões.

Palavras-chave: Abordagens da controladoria. Trabalhos publicados. Congresso USP de Controladoria e Contabilidade.

\begin{abstract}
The study identifies the approach of comptrollership on papers published in the annals of the USP Congress on Comptrollership and Accounting from 2001 to 2006, based on documentary research and descriptive denotation. The results show that in the conceptual perspective there is no concern in defining the term comptrollership and neither its relationship with other areas of knowledge. In the procedural perspective, there is no consensus about the typical activities but it stands out the one related to information systems. In the organizational perspective, the comptrollership is not seen as a formally established organizational unit with power of decision, but as an administrative unit that supports the decision-making.
\end{abstract}

Keywords: Approaches of Comptrollership. Published papers. USP Congress on Comptrollership and Accounting.

\section{Introdução}

Com o advento da globalização, as empresas se encontram inseridas em um contexto de rápidas e constantes mudanças. Entre as mudanças que impactam sobre as empresas, a que tem maior relevância é o acirramento da competitividade, devido a sua expressão ter expandido do nível nacional para o internacional. $\mathrm{O}$ conhecimento, o controle e o planejamento são alguns dos principais fatores que podem estabelecer as oportunidades ou as ameaças à sobrevivência das empresas, pois exigem das mesmas respostas rápidas e eficazes ao alcance de seus objetivos. Neste contexto, pode-se observar a importância da controladoria como órgão responsável pelo processo de gestão dentro das empresas.

Beschorner e Lang (2000, p. 2) destacam que a "controladoria permite a gerência adaptar a empresa às mudanças no ambiente e nos processos de planejamento, e também realizar todas as funções de coordenação". Além de ser um órgão administrativo, a controladoria também se destaca por ser um ramo do conhecimento. Segundo Mosimann e Fisch (1999, p. 88), "o órgão administrativo controladoria tem por finalidade garantir informações adequadas ao processo decisório".

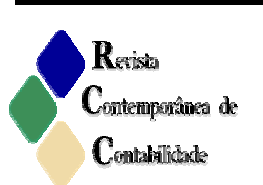


No que se refere à controladoria como ramo do conhecimento, esta por sua vez representa "o conjunto de princípios, procedimentos e métodos oriundos das ciências da Administração, Economia, Psicologia, Estatística e, principalmente, da Contabilidade, que se ocupa da gestão econômica das empresas, com a finalidade de orientá-las para a eficácia" (MOSIMANN; FISCH, 1999, p. 99).

De acordo com Mambrini, Beuren e Colauto (2002, p. 46), "a controladoria opera dentro de suas próprias concepções sobre a gestão empresarial, reunindo teorias, conceitos e métodos de várias ciências, além de servir como órgão integrador e coordenador da atuação eficaz dos gestores". Neste sentido, cabe ressaltar a importância de estudar a controladoria como um ramo do conhecimento.

Para que se possa estudar a controladoria como ramo de conhecimento é necessário ter definido adequadamente um arcabouço teórico sobre o tema. Porém, de acordo com pesquisa de Borinelli (2006, 102), "não são muitos os autores que empreendem a tarefa de definir o ramo do conhecimento controladoria comparativamente com o número de autores que a definem enquanto unidade organizacional".

Borinelli (2006), em sua tese de doutorado, procurou sistematizar o conhecimento teórico sobre controladoria por meio de uma análise crítica sobre a literatura existente numa estrutura teórica, sendo que esta foi denominada de Estrutura Conceitual Básica de Controladoria (ECBC). Para esta estrutura, o autor definiu três abordagens de estudo e de organização da controladoria, as quais foram assim denominadas: Perspectiva 1, ramo de conhecimento (aspectos conceituais); Perspectiva 2, aspectos procedimentais (como funciona); Perspectiva 3, aspectos organizacionais (como se materializa nas organizações). Considerando a proposta de Estrutura Conceitual Básica de Controladoria (ECBC) de Borinelli (2006), realizou-se este estudo.

O levantamento bibliográfico realizado por Borinelli (2006) permitiu a formulação de uma estrutura de conceitos relativos à controladoria. Porém, este levantamento demonstrou que há posições significativamente diferenciadas entre os autores em relação ao assunto. Nesse contexto, para a realização do estudo formulou-se a seguinte questão de pesquisa: Qual é a abordagem dada à controladoria pelos trabalhos publicados nos anais do Congresso USP de Controladoria e Contabilidade no período de 2001 a 2006? O objetivo do artigo é identificar a abordagem dada à controladoria pelos trabalhos publicados nos anais do Congresso USP de Controladoria e Contabilidade no período de 2001 a 2006.

Para tanto, utilizou-se como parâmetro as perspectivas destacadas por Borinelli (2006) em sua tese de doutorado. A busca de respostas à questão de pesquisa deu-se por meio de pesquisa documental, de cunho descritivo e abordagem quantitativa da situação-problema. A relevância deste estudo baseia-se em diversas pesquisas anteriores realizadas sobre o tema, onde se evidencia a necessidade de estudos sobre controladoria, pelo fato desta possuir uma base teórica que se encontra ainda em fase de desenvolvimento.

As reflexões realizadas a respeito da controladoria em trabalhos publicados por Moriki e Martins (2003) e Martins e Silva (2005), por meio do levantamento de dados e análise das referências bibliográficas das dissertações, teses e artigos, demonstram que, apesar de estes estudos serem de fácil acesso, os livros ainda predominam como fontes de referência. Algumas pesquisas exploram especificamente a divergência no entendimento dos objetivos, funções e atividades da controladoria na literatura existente (RICARDINO, 2005; BORINELLI, 2006; LUNKES et al., 2009).

Outros estudos foram desenvolvidos com o propósito de compreender o 
desenvolvimento da controladoria nas organizações (BORINELLI, 2006) e sua abordagem em pesquisas acadêmicas (BEUREN, SCHLINDWEIN e PASQUAL, 2007; GERIGK et al., 2007; BEUREN, BOGONI e FERNANDES, 2008; GRANDE e BEUREN, 2008; BEUREN e SILVA, 2010; LAUDELINO, NAVARRO e BEUREN, 2010).

O estudo está estruturado em cinco partes, iniciando com esta introdução. Em seguida, faz uma incursão nos aspectos teóricos da controladoria para fundamentar a pesquisa. $\mathrm{Na}$ sequiência apresenta o método e os procedimentos utilizados na pesquisa. Por fim, analisa os dados coletados e apresenta as considerações finais relativos o estudo realizado.

\section{Referencial Teórico}

Os primórdios da controladoria são obscuros e não se tem uma origem aceita de modo universal. Segundo Ricardino (2005, 7), diversas explicações foram estabelecidas, porém "elas careciam de um elo que estabelecesse uma relação com o passado, quando as práticas gerenciais já existiam". No entanto se concorda com a premissa que, devido ao aumento da complexidade das organizações empresariais, os gestores têm cada vez mais necessidade de informações ágeis e úteis para apoio à tomada de decisão.

Embora a controladoria tenha adquirido maior relevância nas organizações nas últimas décadas, observa-se na obra de Kanitz (1976, p. 5), considerando o ano da publicação, que não se trata de matéria tão recente, ainda que com concepção diversa da atual, quando expõe que a controladoria "originou-se de pessoas que exerciam cargos de responsabilidade no departamento contábil, ou no departamento financeiro". A explicação decorre do fato de "possuírem estes profissionais, em função do cargo que ocupavam, uma visão ampla da empresa, que os tornou capazes de detectar as dificuldades e propor soluções".

O profissional cntroller aparece como a figura responsável por uma espécie de centro receptor de informações e busca, a partir de análise e interpretação dos dados, produzir relatórios que venham a suprir a necessidade informacional dos gestores das organizações. Floriani (2000, p. 11) menciona que, "como as informações produzidas pelo departamento de contabilidade são de natureza quantitativa, esses profissionais passam a ser indispensáveis para exercerem a função, embora a controladoria não se resuma em administrar o sistema contábil da empresa".

A função do controller independe das organizações possuírem ou não um departamento ou setor denominado especificamente de controladoria. A abrangência das funções do controller não é uniforme na literatura que versa sobre o tema, logo também espera-se que não seja nas organizações. Contudo, é a controladoria que de fato gerencia o processo informacional de suporte ao processo gestão.

Autores como Piai (2000), Favretto (2001), Lapolli (2003), Souza (2007) confirmaram em suas pesquisas que uma das principais contribuições da controladoria para com as organizações está relacionada à estruturação e gerenciamento de um sistema de informação, capaz de suportar o processo decisório. Frezatti, Aguiar e Rezende (2007, p. 129) ressaltam que "a satisfação dos usuários aumenta se os atributos do sistema permitem aos usuários a obtenção de informações úteis".

O controller, que é a pessoa responsável pela controladoria, muitas vez se confunde com o departamento que representa. Borinelli (2006, p. 105) define a controladoria como "um conjunto de conhecimentos que se constituem em bases teóricas e conceituais de ordens

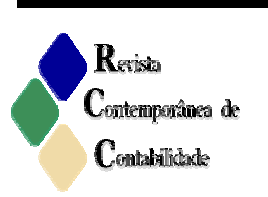


operacional, econômica, financeira e patrimonial, relativas ao controle do processo de gestão organizacional".

Este complexo de atividades, que produz uma série de informações sob a responsabilidade da controladoria, objetiva exclusivamente a continuidade das empresas, o cumprimento de seus objetivos e da sua missão (MOSIMANN; FISCH, 1999). A sua execução se fundamenta em um arcabouço teórico pertinente e na práxis das organizações.

Borinelli (2006), em sua tese de doutorado, apresenta subsídios para o entendimento de como a sistematização da controladoria está organizada dentro de uma estrutura conceitual básica. Para isto, define controladoria sobre três abordagens de estudo e organização: Perspectiva 1, ramo de conhecimento (aspectos conceituais); Perspectiva 2, aspectos procedimentais (como funciona); Perspectiva 3, aspectos organizacionais (como se materializa nas organizações).

A perspectiva 1 trata sobre os aspectos conceituais da controladoria. Nesta perspectiva o autor identifica em seu estudo as diferentes definições a respeito do que é a controladoria, qual o seu objeto de estudo, o posicionamento da controladoria no campo das ciências e, por fim, evidencia as ramificações e subdivisões dessa área.

Uma vez abordados os aspectos conceituais, Borinelli (2006) buscou evidenciar como a Perspectiva 1 se materializa na prática. Para tanto, na Perspectiva 2, o autor pesquisa sobre as atividades, as funções e os artefatos por meio dos quais a controladoria se materializa em sua aplicação nas organizações.

Por fim, a finalidade da Perspectiva 3 é entender como a definição, o objeto de estudo, as atividades e as funções da controladoria acontecem dentro das organizações. Isto se dá através do estudo da estruturação da unidade organizacional que desenvolve atividades e funções de controladoria.

Ao sistematizar a estrutura conceitual básica de controladoria em sua tese de doutorado, Borinelli (2006) relata que a maior dificuldade encontrada na realização da pesquisa se deu pela divergência entre os autores. Por outro lado, Beschorner, Lang e Russ. (1999) destacam que a controladoria, por ser um emaranhado de conhecimentos, é capaz de fornecer informações para os diversos setores da empresa de acordo com a necessidade de cada um deles.

Um dos principais pontos de divergência entre os diversos autores pesquisados por Borinelli (2006) é a identificação do objeto de estudo da controladoria, ou seja, qual é o campo de aplicação ou área de eficácia. Em relação a este aspecto o autor afirma que "o objeto de estudo da controladoria são as organizações, ou seja, o modelo organizacional como um todo".

Neste sentido, Oliveira (2009, p. 66) adverte que "subsidiar o processo de gestão envolve ajudar na adequação do processo de gestão à realidade da empresa ante seu meio ambiente, o que se materializa tanto no suporte à estruturação do processo de gestão como no efetivo apoio às decisões tomadas em suas várias fases". Corrobora-se assim que objeto de estudo da controladoria são as organizações.

Segundo Borinelli (2006), apesar de haver divergências entre os autores que escrevem sobre a controladoria, é importante ressaltar que existem pontos comuns entre os mesmos e que estes, por sua vez, são as peças chave para a estruturação de novos trabalhos sobre o assunto. Assim, as três perspectivas preconizadas pelo autor, para a concepção da Estrutura Conceitual Básica de Controladoria, embasaram a presente pesquisa. 


\section{Método e Procedimentos da Pesquisa}

Para o desenvolvimento do estudo realizou-se uma pesquisa descritiva, com abordagem quantitativa e de cunho documental, uma vez que o objeto de estudo foram os trabalhos publicados nos anais do Congresso USP de Controladoria e Contabilidade no período de 2001 a 2006. No que concerne à pesquisa descritiva, de acordo com Gil (2002), esta tem como principal finalidade descrever características de determinada população ou fenômeno ou o estabelecimento de relações entre as variáveis. Este aspecto implica utilização de técnicas padronizadas de coleta de dados.

No que concerne à pesquisa documental, Gil (2002, p. 45) explica que ela "baseia-se em materiais que ainda não receberam um tratamento analítico ou que podem ser reelaborados de acordo com os objetivos da pesquisa". Delimitou-se como base para de estudo o Congresso USP de Controladoria e Contabilidade pelo fato deste evento ser especificamente da área contábil e classificado como EA (Evento A) no Qualis CAPES (Coordenação de Aperfeiçoamento de Pessoal de Nível Superior - CAPES da área de Administração, Ciências Contábeis e Turismo). O período considerado de 2001 a 2006 decorre do fato desse evento ter iniciado em 2001.

Para o levantamento dos dados buscou-se identificar os trabalhos que foram apresentados neste evento, no período determinado, e que tratam de controladoria e/ou do controller. Para tanto, primeiramente identificou-se, por meio de contagem simples, o número de trabalhos em cada ano que contém a palavra controladoria e/ou controller no título, no resumo ou no texto. Os dados levantados estão demonstrados na Tabela 1.

Tabela 1 - Relação de trabalhos contendo a palavra controladoria e/ou controller

\begin{tabular}{|c|c|c|c|c|}
\hline \multirow{2}{*}{\multicolumn{2}{|c|}{$\begin{array}{c}\text { Congresso USP } \\
\text { Ano dos anais pesquisados } \\
\end{array}$}} & \multicolumn{2}{|c|}{ Número de observações } & \multirow{2}{*}{$\begin{array}{l}\text { Total } \\
\text { Geral }\end{array}$} \\
\hline & & Controladoria & Controller & \\
\hline \multirow{6}{*}{ 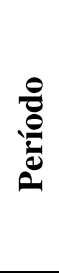 } & 2001 & 5 & 0 & 5 \\
\hline & 2002 & 1 & 0 & 1 \\
\hline & 2003 & 3 & 0 & 3 \\
\hline & 2004 & 1 & 0 & 1 \\
\hline & 2005 & 41 & 7 & 48 \\
\hline & 2006 & 67 & 8 & 75 \\
\hline \multicolumn{2}{|c|}{ Totais } & 118 & 15 & 133 \\
\hline
\end{tabular}

Fonte: Dados da pesquisa.

Nos anais do Congresso USP de Controladoria e Contabilidade do período pesquisado, foram encontrados 133 trabalhos que abordam, em algum momento, o termo controladoria e/ou controller. Todos os trabalhos publicados nos anais foram acessados. No entanto, para análise dos dados optou-se por delimitar uma amostra de 44 trabalhos, representando $33 \%$ da população encontrada. Para a seleção dos 44 trabalhos foi considerado um intervalo múltiplo (a cada 3 trabalhos), o que determinou o número de trabalhos a serem analisados. Portanto, trata-se de amostragem probabilística sistemática, uma vez que foram selecionados os trabalhos com base em intervalos definidos.

Marconi e Lakatos (2002) destacam que a amostragem probabilística tem como principal característica a possibilidade de ser submetida a tratamento estatístico. A partir da seleção da amostra, utilizando-se da abordagem quantitativa, procurou-se identificar e

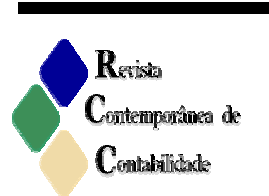


analisar, de acordo com as perspectivas propostas por Borinelli (2006) em sua tese de doutorado (perspectivas conceitual, procedimental e organizacional), quais as abordagens encontradas nos trabalhos publicados no Congresso USP de Controladoria e Contabilidade. Richardson (1999, p.70) menciona que a abordagem quantitativa "caracteriza-se pelo emprego de quantificação tanto das modalidades de coleta de informações, quanto no tratamento delas por meio de técnicas, desde as mais simples [...], às mais complexas".

Como principal limitação da pesquisa destaca-se a busca delimitada das palavras controladoria e/ou controller. É possível que se a busca fosse realizada pelos artefatos da controladoria, por exemplo Balanced Scorecard, Activity Based Costing, Custeio Meta, o número de trabalhos seria bastante ampliado. Outra limitação diz respeito a impossibilidade de aplicar os resultados da pesquisa a todos os eventos científicos relacionados à área da Contabilidade que constam no Sistema Qualis da CAPES. Portanto, a estratégia da pesquisa, ao mesmo tempo que limita, também delimita o escopo do estudo.

\title{
4 Descrição e Análise dos Resultados da Pesquisa
}

À luz das três perspectivas propostas por Borinelli (2006) para a definição da Estrutura Conceitual Básica da Controladoria, procedeu-se a análise dos trabalhos publicados nos anais do Congresso USP de Controladoria e Contabilidade no sentido de identificar os que contém as palavras controladoria e/ou controller no título, no resumo ou no texto.

Para tanto, inicialmente elaborou-se um check list, adaptado da tese de doutorado de Borinelli (2006), dos elementos de análise em cada perspectiva, cuja finalidade principal foi facilitar a tabulação dos dados, para sua posterior análise.

\subsection{Perspectiva I: Aspectos Conceituais}

Nesta perspectiva buscou-se identificar os aspectos conceituais e as subdivisões da controladoria. Borinelli (2006, p. 95) cita que:

\begin{abstract}
a Perspectiva 1 diz respeito ao estudo da área de conhecimento denominada Controladoria. Trata-se de defini-la enquanto ramo, campo ou área do conhecimento humano. Nesse sentido, inicialmente, dois pontos integram a ECBC: o que é Controladoria e qual seu objeto de estudo. Em suma, busca-se evidenciar a essência desse ramo do saber.
\end{abstract}

Partindo-se dessa definição, na Tabela 2 apontam-se os trabalhos pesquisados com seu respectivo enquadramento na Abordagem Conceitual.

Tabela 2 - Análise sobre a Perspectiva I de Borinelli (2006) - Aspectos Conceituais

\begin{tabular}{|c|c|c|c|}
\hline \multirow{8}{*}{ 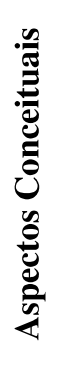 } & & Fr. Absoluta & Fr. Relativa \% \\
\hline & 1 DEFINIÇÃO & 7 & 6,86 \\
\hline & 2 OBJETO & & \\
\hline & 2.1 Processo (Modelo) de Gestão como todo & 9 & 8,82 \\
\hline & 2.2 Necessidades Informacionais (Modelos decisão) & 11 & 10,78 \\
\hline & 2.3 Processo de formação de Resultados Operacionais & 1 & 0,98 \\
\hline & 3 RAMOS DA CIÊNCIA & & \\
\hline & 3.1 Contabilidade & 26 & 25,49 \\
\hline
\end{tabular}




\begin{tabular}{|c|c|c|}
\hline 3.2 Administração & 4 & 3,92 \\
\hline 3.3 Economia & 5 & 4,90 \\
\hline 3.4 Direito & 1 & 0,98 \\
\hline 3.5 Estatítica & 4 & 3,92 \\
\hline 3.6 Matemática & 1 & 0,98 \\
\hline 3.7 Psicologia & 3 & 2,94 \\
\hline 3.8 Sociologia & 1 & 0,98 \\
\hline 4 SUBDIVISÕES DA CONTROLADORIA & & \\
\hline 4.1 Quanto à Natureza em que se aplica & 0 & 0,00 \\
\hline 4.1.1 Controladoria Empresarial & 15 & 14,71 \\
\hline 4.1.2 Controladoria Pública & 4 & 3,92 \\
\hline 4.1.3 Controladoria em Entidades do $3^{\circ}$ Setor & 1 & 0,98 \\
\hline 4.2 Quanto à área de Eficácia dentro da Organização & 0 & 0,00 \\
\hline 4.2.1 Controladoria Corporativa (pensa o todo) & 2 & 1,96 \\
\hline 4.2.2 Controladoria de Unidade (Descentralizadas) & 1 & 0,98 \\
\hline
\end{tabular}

Fonte: Dados da pesquisa.

Como se observa na Tabela 2, dos 44 trabalhos analisados, apenas 7, representando $6,86 \%$, definem controladoria. Nos trabalhos pesquisados foram constatadas 11 observações, ou seja, $10,78 \%$ dos trabalhos reportam que como objeto a controladoria tem seu enfoque maior evidenciado na necessidade informacional (modelos de decisão), seguido de foco no processo (modelo) de gestão como um todo, com 9 citações, representando 8,82\%.

Nakagawa (1987, p. 2) já ressaltava que, "cabe ao controller a tarefa de projetar e implementar e manter um sistema de informações capaz de atender adequadamente as necessidades informativas do processo de planejamento [...]" da empresa, bem como apoiar a tomada de decisão. Os achados da pesquisa também coadunam com estudos de Piai (2000), Favretto (2001), Lapolli (2003) e Souza (2007), que identificaram a controladoria como o setor responsável pelo gerenciamento dos sistemas de informação da empresa.

Ainda procedendo-se a análise dos dados encontrados na Perspectiva I, observa-se que do total dos trabalhos analisados, 26 trabalhos, representando 25,49\%, fazem relação da controladoria com o ramo da ciência denominada contabilidade. Este resultado não surpreende, já que é inerente ao escopo da contabilidade um conjunto de conhecimentos relativos à organização, mensuração, sistematização e comunicação das informações relativas aos fatos e ações das empresas.

As demais áreas do conhecimento abordadas por Borinelli (2006) em sua tese de doutorado (Administração, Economia, Direito, Estatística, Matemática, Psicologia e Sociologia), aparecem com pouca freqüência. Ainda que estas áreas tenham sido mencionadas com pouca frequiência nos trabalhos analisados, talvez porque a finalidade da abordagem tenha sido diversa da que se está considerando, são áreas de conhecimentos importantes para o desenvolvimento das funções e atividades da controladoria.

Por fim, no que se refere à análise das subdivisões da controladoria, 15 trabalhos abordam a Controladoria Empresarial, considerando-se a natureza de sua aplicação. Por sua vez, apenas 2 trabalhos apresentam a Controladoria como Unidade Corporativa, enquanto área de eficácia dentro da organização, Denota-se nas abordagens que a ênfase está na controladoria em conformidade às suas origens, isto é, seu desenvolvimento nas organizações empresariais e não em atividades com destaque mais recente, como é o caso do terceiro setor.

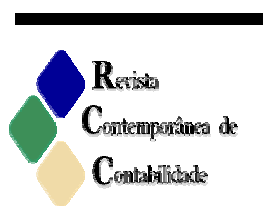




\subsection{Perspectiva II: Aspectos Procedimentais}

Na perspectiva II busca-se identificar os aspectos de procedimento da controladoria. Segundo Borinelli (2006, p. 96), nos aspectos procedimentais:

são estudados os elementos relativos ao funcionamento da controladoria, quando essa área do conhecimento é levada às entidades. Assim, os componentes dessa abordagem na ECBC são as atividades e funções típicas de Controladoria, além dos artefatos (instrumentos) utilizados para operacionalizar-se.

Na Tabela 3 mostra-se a inserção da controladoria dentro da Perspectiva II: Aspectos Procedimentais, com base nos 44 trabalhos pesquisados.

Tabela 3 - Análise sobre a Perspectiva II de Borinelli (2006) - Aspectos Procedimentais

\begin{tabular}{|c|c|c|c|}
\hline \multirow{25}{*}{ 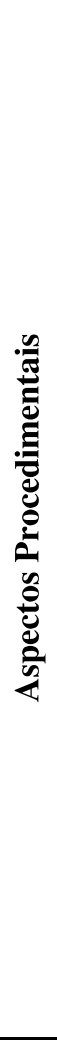 } & & Fr. Absoluta & Fr. Relativa \% \\
\hline & 1 FUNÇÕES & & \\
\hline & 1.1 Função Contábil & 8 & 7,27 \\
\hline & 1.2 Função Gerencial & 11 & 10,00 \\
\hline & 1.3 Função de Custos & 8 & 7,27 \\
\hline & 1.4 Função Tributária & 4 & 3,64 \\
\hline & 1.5 Função de Proteção e Controle de Ativos & 2 & 1,82 \\
\hline & 1.6 Função de Controle Interno & 9 & 8,18 \\
\hline & 1.7 Função de Controle de Riscos & 1 & 0,91 \\
\hline & 1.8 Função de Gestão de Informações & 27 & 24,55 \\
\hline & 1.9 Outras Funções & 9 & 8,18 \\
\hline & 2 ATIVIDADES DA CONTROLADORIA & & \\
\hline & 2.1 Planejamento (estabelecer objetivos) & 9 & 8,18 \\
\hline & 2.2 Elaboração do Orçamento & 2 & 1,82 \\
\hline & 2.3 Execução Orçamentária & 1 & 0,91 \\
\hline & 2.4 Controle Orçamentário & 1 & 0,91 \\
\hline & 2.5 Medidas Corretivas & 1 & 0,91 \\
\hline & 2.6 Avaliação de Desempenho & 4 & 3,64 \\
\hline & 3 CONTROLADORIA E SUA RELAÇÃO COM & & \\
\hline & 3.1 Controle Interno & 7 & 6,36 \\
\hline & 3.2 Auditoria Interna & 0 & 0,00 \\
\hline & 4 ARTEFATOS DE CONTROLADORIA & & \\
\hline & 4.1 Métodos, Critérios e Sistemas de Custeio & 3 & 2,73 \\
\hline & 4.2 Métodos de Mensuração, Avaliação e Desempenho & 2 & 1,82 \\
\hline & 4.3 Filosofias e Modelos de Gestão (Kaizen, BSC) & 1 & 0,91 \\
\hline
\end{tabular}

Fonte: Dados da pesquisa.

Conforme os dados apresentados na Tabela 3, nota-se que diversas funções e atividades são atribuídas como sendo de responsabilidade da controladoria. Os achados reforçam os argumentos de Borinelli (2006) em sua tese, quando este afirma que não há consenso entre os autores sobre quais são as atividades típicas da controladoria.

No que se refere às funções da controladoria, nos trabalhos analisados a função evidenciada com maior predominância é a de Gestor das Informações, com 27 citações. A geração das informações implica que um dos artefatos da controladoria seja o Sistema de Informações. Kanitz (1976) já destacava que uma das principais funções da controladoria nas organizações está relacionada ao processo de gestão do seu sistema de informação. Logo, 
estudar o ambiente onde a controladoria está inserida pode contribuir para um melhor entendimento da controladoria enquanto ramo do conhecimento.

Das atividades mais citadas nos trabalhos pesquisados observa-se o Planejamento, como destaque, com 9 citações. Beschorner e Lang (2000) ressaltam a importância da controladoria por esta contribuir para que a gerência possa adaptar a empresa às mudanças no ambiente e nos processos de planejamento. A atividade de Avaliação de Desempenho também é citada, embora com menor intensidade. Esperava-se que ela tivesse maior ênfase, já que é apontada como uma importante atribuição da controladoria por diversos autores, como Kanitz (1976), Mosimann e Fisch (1999).

A relação da controladoria com o controle interno registra 7 observações, cuja reduzida quantidade absoluta talvez possa ser explicada por se tratar de uma atividade ainda recente nas abordagens de obras nacionais. Em relação aos artefatos da controladoria, observa-se que os mais citados são Métodos, Critérios e Sistemas de Custeio, constatados em três trabalhos. Essa pequena quantidade pode ser em decorrência do modo como foram selecionados os trabalhos para esta pesquisa, isto é, as palavras controladoria e/ou controller e não artefatos da controladoria.

\subsection{Perspectiva III: Aspectos Organizacionais}

Os aspectos organizacionais abordados por Borinelli (2006, p. 96) na Perspectiva Organizacional:

discutem como as atividades e funções contempladas na abordagem anterior estão disseminadas nos vários órgãos ou unidades das organizações. Nesse estágio, busca-se entender a Controladoria enquanto unidade administrativa organizacional, ou seja, como um subsistema do sistema organizacionalformal.

Na Tabela 4, apresentam-se as principais inserções da controladoria nesta perspectiva, constatadas nos 44 trabalhos pesquisados.

Tabela 4 - Análise sobre a Perspectiva III de Borinelli (2006) - Aspectos Organizacionais

\begin{tabular}{|c|c|c|c|}
\hline \multirow{18}{*}{ 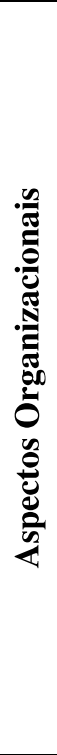 } & & Fr. Absoluta & Fr. Relativa \\
\hline & 1 UNIDADE ORGANIZACIONAL-CONTROLADORIA & 7 & 13,46 \\
\hline & 2 MISSÃO & 7 & 13,46 \\
\hline & 3 OBJETIVOS & 0 & 0,00 \\
\hline & 4 POSIÇÃO HIERÁRQUICA & & \\
\hline & 4.1 Órgão de Linha & 3 & 5,77 \\
\hline & 4.2 Órgão de Staff & 12 & 23,08 \\
\hline & 5 ORGANIZAÇÃO INTERNA & & \\
\hline & 5.1 Contabilidade Gerencial ou Financeira & 3 & 5,77 \\
\hline & 5.2 Contabilidade Societária & 1 & 1,92 \\
\hline & 5.3 Contabilidade Gerencial & 0 & 0,00 \\
\hline & 5.4 Planejamento, Orçamento e Controle & 1 & 1,92 \\
\hline & 5.5 Contabilidade de Custos & 3 & 5,77 \\
\hline & 5.6 Contabilidade Fiscal ou Tributária & 0 & 0,00 \\
\hline & 5.7 Seguros e Controle Patrimonial & 0 & 0,00 \\
\hline & 5.8 Controles Internos & 3 & 5,77 \\
\hline & 5.9 Riscos & 3 & 5,77 \\
\hline & 5.10 Sistemas de Informação & 9 & 17,31 \\
\hline
\end{tabular}

Fonte: Dados da pesquisa. 
De acordo com os dados da Tabela 4, apenas 7 trabalhos tratam a controladoria como uma unidade organizacional formalmente constituída. Da mesma forma, 7 trabalhos mencionam a missão da controladoria. No entanto, nenhum dos trabalhos pesquisados reporta os objetivos desse órgão. Essa perspectiva de análise não se constata de forma isolada na literatura como foi proposto por Borinelli (2006), o que pode ter resultado em pouca atenção dedicada a esses aspectos da controladoria.

Observa-se também que 12 trabalhos descrevem a controladoria como um órgão de staff, sem poder de decisão, o que reflete a tendência das Perspectivas anteriores (I e II), as quais reportam a controladoria como a gestora das informações dentro da organização. Uma espécie de centro processador de informações úteis à tomada de decisão. Apesar de ser uma função amplamente destacada na literatura, o papel da controladoria não se restringe à gestão dos sistemas de informação.

Leal, Tome e Yamashita (2006, p. 5) afirmam que "os sistemas de informação são parte essencial da empresa. Eles armazenam dados referentes não apenas a clientes, como também os resultados alcançados durante os anos de atividade da organização, informações sobre os funcionários, os preços obtidos com os fornecedores, dados da concorrência, etc". Os autores salientam que "toda essa gama de conhecimento é analisada, e suas combinações trazem respostas para muitas perguntas feitas para uma boa relação com o ambiente e a busca por uma organização perfeita".

No que se refere à organização interna da controladoria, nota-se com a realização desta pesquisa que este órgão divide-se em diversas áreas (Gerencial, Societária, Custos, etc.), não seguindo um determinado padrão consolidado, como ocorre em outras áreas da empresa. Isto pode decorrer do fato de que a definição da organização interna nas empresas dá-se em função de sua própria estrutura, atividade e/ou característica.

\section{Conclusões}

O artigo objetivou identificar a abordagem dada à controladoria pelos trabalhos publicados nos anais do Congresso USP de Controladoria e Contabilidade no período de 2001 a 2006. Para tanto, realizou-se pesquisa descritiva, por meio de pesquisa documental, com abordagem quantitativa. Para a tabulação e análise dos dados coletados nos 44 trabalhos selecionados, tomaram-se como referência os elementos considerados nas três perspectivas destacadas por Borinelli (2006) em sua tese de doutorado.

Os resultados da pesquisa evidenciam em relação à Perspectiva I, Aspectos Conceituais, que a preocupação com a definição de controladoria é mínima ou inexiste. Mesmo na literatura relacionada a essa área de conhecimento não se tem uma definição de controladoria e diversas vezes ela é confundida com as atribuições do controller, que é a pessoa responsável por esse órgão nas organizações.

Ainda nesta mesma perspectiva, mas na relação da controladoria com outras áreas do conhecimento, a contabilidade aparece como a principal ciência. A natureza de uma das principais atribuições da controladoria, o gerenciamento das informações de suporte ao processo decisório, remete a esta constatação, já que a contabilidade é a provedora de informações para usuários internos e externos das organizações, exigindo, portanto, conhecimentos correlatos aos que perpassam a controladoria e vice-versa. 
Como último elemento de análise relativo aos Aspectos Conceituais, denota-se ênfase na abordagem da aplicação da controladoria na gestão empresarial, particularmente como um órgão de suporte ao processo de gestão e responsável pela geração de informações para a tomada de decisão. A controladoria encontrou um ambiente favorável ao seu desenvolvimento na expansão das empresas, seja em decorrência de sua maior complexidade ou da descentralização da gestão, o que pode ter contribuído para o foco na abordagem da controladoria na gestão empresarial.

Sobre os Aspectos Procedimentais, Perspectiva II, não se observou um consenso entre os autores sobre quais são as atividades típicas da controladoria. Certamente esta constatação se deve ao enfoque de cada trabalho desenvolvido, com finalidade específica de uma abordagem pretendida para o evento considerado na pesquisa. Contudo, nos resultados da pesquisa observa-se a importância atribuída à geração das informações pela controladoria, indicando como principal artefato apontado pelos estudos os sistemas de informação.

Por fim, quanto aos Aspectos Organizacionais, Perspectiva III, verificou-se que os trabalhos analisados não estão preocupados em tratar a controladoria como uma unidade organizacional, formalmente constituída, com poder de decisão, mas sim, como unidade administrativa, capaz de subsidiar com informações a tomada de decisão. Este é apenas um dos aspectos de preocupação da controladoria, mas a unidade organizacional deve ter um espectro mais amplo de atuação na organização para cumprir na íntegra a sua missão, suas funções e atividades.

Os resultados encontrados na pesquisa corroboram os argumentos apresentados por Borinelli (2006) em relação ao fraco arcabouço teórico existente sobre o tema. Grande e Beuren (2008), limitando-se aos títulos pesquisados, também concluíram que as abordagens do tema controladoria em livros nacionais ainda é incipiente, principalmente nos aspectos conceituais e da controladoriaa como unidade organizacional. Conclui-se que os achados desta pesquisa, da mesma forma como nas pesquisas anteriores, sugerem que mais pesquisas e estudos são necessários sobre a teoria e a práxis da controladoria para criar um arcabouço consolidado dessa disciplina.

Desta forma, acredita-se que o objetivo do estudo foi alcançado, à medida que se pode identificar a abordagem dada à controladoria pelos trabalhos publicados nos anais do Congresso USP de Controladoria e Contabilidade no período de 2001 a 2006, tendo como referência as perspectivas propostas por Borinelli (2006) em sua tese de doutorado. Adicionalmente, com a pesquisa foi possível contribuir para a identificação de novas oportunidades de pesquisas a serem desenvolvidas em controladoria.

Dadas as limitações deste estudo, recomenda-se para futuras pesquisas sobre o tema investigado, aplicar este constructo a outros eventos científicos e em periódicos relacionados à área da Contabilidade que constam no Sistema Qualis da CAPES. Também recomenda-se avançar em pesquisas teóricas e empíricas que objetivem consolidar uma Estrutura Conceitual Básica de Controladoria.

\section{Referências}

ANDRADE, M.M. Introdução à metodologia do trabalho cientifico. 6. ed. São Paulo: Atlas, 2005.

BESCHORNER, D.; LANG H.A. Controllership in Japan - is there Western-style

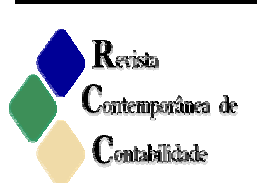


Controllership in Japanese companies? In: Annual Meeting 2000, Nov 23rd-25th INSEAD's. Anais ... Asian Campus, Singapore, 2000.

BESCHORNER, D.; LANG H.A.; RUSS, J. Intangibles and Competition: a Theoretical Approach from de Controller's View. Nistads Workshop 1999, Dec $29^{\text {th }}-31^{\text {st }}$. New Delphi.

BEUREN, I. M.; BOGONI, N. M.; FERNANDES, L. Análise da abordagem da controladoria em dissertações dos programas de pós-graduação em Ciências Contábeis. Revista Brasileira de Gestão e Negócios (RBGN), São Paulo, v. 10, n. 28, p. 249-263, jul./set. 2008.

BEUREN, I. M.; SCHLINDWEIN, A. C.; PASQUAL, D. L. Abordagem da controladoria em trabalhos publicados no EnANPAD e no Congresso USP de Controladoria e Contabilidade de 2001 A 2006. Revista de Contabilidade e Finanças (USP), São Paulo, v. 18, n. 45, p. 22-37, set./dez. 2007.

BEUREN, I. M.; SILVA, A. J. Abordagens da controladoria em artigos publicados em periódicos dos programas de pós-graduação em Ciências Contábeis recomendados pela CAPES. Revista de Contabilidade da UEM, Maringá, v. 29, n. 3, p. 09-21, set./dez. 2010.

BORINELLI, M. Estrutura Conceitual Básica de Controladoria: sistematização à luz da teoria e da práxis. 2006. 341 f. Tese (Doutorado em Contabilidade) - Departamento de Contabilidade e Atuária da Faculdade de Economia, Administração e Contabilidade, Universidade de São Paulo, São Paulo, 2006.

COORDENAÇÃO DE APERFEIÇOAMENTO DE PESSOAL DE NÍVEL SUPERIOR (CAPES). Disponível em: <http://www.qualis.capes.gov.br >. Acesso em: 11 mar. 2007.

FAVRETTO, J. A informação da controladoria nas agroindústrias de Santa Catarina. 2001. 89 f. Dissertação (Mestrado em Administração: Gestão Moderna de Negócios) - Programa de Pós Graduação em Administração, Universidade Regional de Blumenau, 2001.

FLORIANI, A.R. A eficiência das informações geradas pela controladoria no processo de gestão em empresas têxteis de Blumenau-SC. Blumenau, 2000. 93 f. Dissertação (Mestrado em Administração: Gestão Moderna de Negócios) - Programa de Pós-Graduação em Administração, da Universidade Regional de Blumenau, 2000.

FREZATTI, F.; AGUIAR, A. B.; REZENDE, A. J. Relacionamento entre atributos da contabilidade gerencial e satisfação do usuário. Revista de Administração Mackenzie, v. 8, n. 2, p. 128-161, 2007.

GERIGK, W.; TARIFA, M. R.; ALMEIDA, L. B.; ESPEJO, M. M. S. B. Controladoria pública municipal na perspectiva dos profissionais do controle externo. ABCustos Associação Brasileira de Custos, v. 2, n. 3, set./dez., 2007.

GIL, A.C. Métodos e técnicas de pesquisa social. 4. ed. São Paulo: Atlas, 2002.

GRANDE, J. F.; BEUREN, I. M. Abordagem da controladoria em livros publicados no Brasil. Revista de Informação Contábil (RIC,) v. 2, n. 1, p. 40-55, jan./mar. 2008.

KANITZ, S.C. Controladoria: teoria e estudos de caso. São Paulo: Pioneira, 1976.

LAPOLLI, P. C. Implantação de sistemas de informações gerenciais em ambientes educacionais. 2003. 115 f. Dissertação (Mestrado em Engenharia de Produção) - Programa de Pós-Graduação em Engenharia de Produção, Universidade Federal de Santa Catarina, 
Florianópolis, 2003.

LAUDELINO, J.; NAVARRO, R. M.; BEUREN, I. M. Análise da abordagem da controladoria nas dissertações e teses dos programas acadêmicos de mestrado e doutorado em Ciências Contábeis no Brasil. Revista de Contabilidade da UFBA, Salvador, v. 4, n. 2, p. 2133, maio/ago. 2010.

LEAL, D.T.B.; TOME, L.H.; YAMASHITA, R.M. O Processo logístico de serviço ao cliente favorecido pela Internet e sistemas de informação digitais. In: $6^{\circ}$ Congresso USP de Controladoria e Contabilidade, 2006, São Paulo. Anais... São Paulo, 2006.

LUNKES, RJ.; SCHNORRENBERGER, D.; GASPARETTO, V.; VICENTE, E.F.R. Considerações sobre as funções da controladoria nos Estados Unidos, Alemanha e Brasil. Revista Universo Contábil, Blumenau, v. 5, n.4, p. 63-75, out./dez., 2009.

MAMBRINI, A.; BEUREN, I.M.; COLAUTO, R.D. A controladoria como unidade administrativa de suporte ao processo de gestão na perspectiva da gestão econômica. Revista do CRCPR, Curitiba/PR, v. 27, n. 133, p. 41-50, 2002.

MARCONI, M.A; LAKATOS, E.M. Técnicas de pesquisa. 5. ed. São Paulo: Atlas, 2002.

MARTINS, G.A.; SILVA, M.B.C. Plataforma teórica - trabalhos dos $3^{\circ}$ e $4^{\circ}$ Congressos USP de Controladoria e Contabilidade: um estudo bibliométrico. In: $5^{\circ}$ Congresso USP de Controladoria e Contabilidade, 2005, São Paulo. Anais... São Paulo, 2005.

MORIKI, A.M.N.; MARTINS, G.A. Análise do referencial bibliográfico de teses e dissertações sobre contabilidade e controladoria. In: $3^{\circ}$ Congresso USP de Controladoria e Contabilidade, 2003, São Paulo. Anais... São Paulo, 2003.

MOSIMANN, C.P.; FISCH, S. Controladoria: seu papel na administração de empresas. São Paulo: Atlas, 1999.

NAKAGAWA, M. Estudo de alguns aspectos de controladoria que contribuem para a eficácia gerencial. Tese (Doutorado em Ciências Contábeis) - Programa de Pós-Graduação em Ciências Contábeis, Departamento de Contabilidade e Atuaria, FEA-USP, 1987.

OLIVEIRA, A.B.S. Controladoria: fundamentos do controle empresarial. São Paulo: Saraiva, 2009.

PIAI, M. A. B. Metodologia para implementação de sistema de controladoria. $2000.174 \mathrm{f}$. Dissertação (Mestrado em Engenharia de Produção) - Programa de Pós-Graduação em Engenharia de Produção, Universidade Federal de Santa Catarina, Florianópolis, 2000.

RICARDINO, A. Contabilidade gerencial e societária: origens e desenvolvimento. São Paulo: Saraiva, 2005.

RICHARDSON, R.J. Pesquisa social: métodos e técnicas. São Paulo: Atlas, 1980.

SOUZA, L. C. A controladoria e a implantação de Sistemas Integrados de Gestão - ERP. 2003. 162 f. Dissertação (Mestrado em Controladoria e Contabilidade Estratégica) - Programa de Pós-Graduação em Ciências Contábeis, do Centro Universitário Álvares Penteado, São Paulo, 2003.

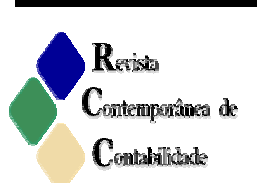

